\title{
Personas - Vínculos familiares no filme Jogo de Cena
}

\author{
Personas - family bonds in the movie Jogo de Cena
}

Mirella Márcia Longo Vieira Lima ${ }^{1}$

A Eduardo Coutinho

RESUMO: Este artigo analisa o filme Jogo de Cena, dirigido por Eduardo Coutinho, ao passo em que este dialoga com obras literárias, como de Carlos Drummond de Andrade e Machado de Assis. Analisamos como ocorre o processo de desvelamento e exposição para várias mulheres, sob uma perspectiva crítica capaz de perceber como Jogo de Cena reedita, em nova versão, o anseio de conhecimento e representação da realidade social do país, uma das marcas do diretor. Resistentes, mas sem idealismos, boa parte das experiências femininas relatadas perpassam dor e melancolia, e em grande medida reverberam lacunas deixadas pelo Estado brasileiro.

PALAVRAS-CHAVES: Eduardo Coutinho; Carlos Drummon de Andrade; Jogo de Cena; representação.

ABSTRACT: This article analyzes the movie Jogo de Cena, directed by Eduardo Coutinho, while the latter dialogues with literary works such as Carlos Drummond de Andrade and Machado de Assis. We analyze how the process of unveiling and exposition for various women occurs, under a critical perspective capable of perceiving as a Scene Game reissue, in a new version, the yearning for knowledge and representation of the country's social reality, one of the director's trademarks. Resistant, but without idealism, a good part of the women's experiences are pain and melancholy, and to a great extent the gaps left by the Brazilian state are reverberated.

KEY-WORDS: Eduardo Coutinho; Carlos Drummond de Andrade; Jogo de Cena; Representation.

Segundo o Instituto Brasileiro de Geografia e Estatística, a composição das famílias vem apresentando, no Brasil, aceleradas alterações. Dentre outras mudanças, os últimos Censos registram crescimento no número de famílias cujas pessoas de referência são mulheres e considerável aumento no número de famílias compostas por mulheres sem cônjuge e com filhos. ${ }^{2}$ Apesar disso, grupos familiares desse tipo parecem ter dificuldade em ascender ao plano das representações culturais brasileiras, mais voltadas para o registro das diversas formas de patriarcado, para a longa agonia do sistema patriarcal, assim como para a sua constante resistência e ainda para os seus resíduos. Nesse sentido, adquire certa

\footnotetext{
${ }^{1}$ Escritora e ensaísta (Autora de Cenas de Amor em Romances do Século XX; A Torre Infinita, entre outros), é Professora Titular do Curso de Letras da UFBA, Universidade Federal da Bahia. E-mail: mimlv1@yahoo.com.br.

2 Ver Censos de 2006 e 2010: www.ibege.gov.br Pelo censo de 2006, um ano antes do filme Jogo de Cena ser lançado, a família tipo mulher sem cônjuge com filhos - que representava, em 2000, 17,4\% das famílias nordestinas e $15,9 \%$ das famílias da região Sudeste - passara a representar 20,1\% e 18,3\%, respectivamente. Mais acentuado nessas duas regiões, o crescimento ocorre em todo o país, primordialmente na área urbana.
} 
excepcionalidade a escolha realizada por Carlos Drummond de Andrade, em Desaparecimento de Luisa Porto, poema centrado na figura de uma mãe solitária em busca da filha perdida ${ }^{3}$. Claramente, nesse texto que integra Novos Poemas, livro publicado em 1948, Drummond recorreu à densidade de uma persona lírica, para melhor evidenciar a inconsistência do debate público. Naquele momento, o escritor mineiro tangencialmente se aproximou da problemática social explicitada nos últimos censos, antecipando aspectos da matéria que seria contemplada pelo cineasta Eduardo Coutinho, em filme de 2007.

Respondendo a um anúncio de jornal, oitenta e três mulheres contaram experiências marcantes em suas vidas. Depois de uma primeira seleção, algumas delas foram entrevistadas e filmadas no Teatro Glauce Rocha, no Rio de Janeiro. Em seguida, atrizes foram convidadas a assumir o lugar das entrevistadas, interpretando livremente as relatoras. Conduzidas pelo cineasta Eduardo Coutinho, essas entrevistas resultaram no filme Jogo de Cena. Operando de modo complexo, o diretor usou diversas estratégias. A inserção de algumas atrizes desconhecidas gerou dúvidas acerca do estatuto de certos depoimentos, ambivalentes entre a confissão e a interpretação. Algumas histórias são narradas apenas pelas pessoas que as vivenciaram, mas outras são repetidas. Uma única história é apresentada apenas por uma atriz. Atrizes também representam histórias de outras atrizes, ou introduzem suas próprias confissões; algumas delas adotam um tom reflexivo, focalizando a arte de representar.

A questão da representação fica realmente bastante grifada pelos procedimentos adotados por Coutinho. Assim, parece natural que a crítica tenha destacado em seu filme uma intenção de evidenciar o estremecimento das fronteiras entre depoimento e interpretação cênica. Afinal, se as depoentes incorporam, diante das câmeras, camadas de artifício, as intérpretes também abrem algum espaço à sinceridade que tende a predominar nas falas confessionais. Contudo, apesar dessa opção formal, parece justo salientar que Jogo de Cena ultrapassa a problemática da representação, alcançando e mesmo, terminando por situar, em seu centro, um imaginário que, atravessando diversas vozes, compõe um discurso que se coletiviza. Tocando diferentes fontes, esse discurso impõe-se, ao modo de uma enunciação pluripessoal associada a fenômenos sociais que constituíam, até então, matéria pouco visível na cena cultural brasileira. Essa escassez na área das representações parece, de fato, impor a dificuldade expressiva que o filme traduz formalmente em sua natureza ambivalente e movediça entre os territórios do documentário e da ficção.

\footnotetext{
${ }^{3}$ Esqueçam a luta política,/ponham de lado preocupações comerciais... Não há gratificação maior do que o sorriso da mãe em festa...Cf: DRUMMOND DE ANDRADE, Carlos. Poesia e Prosa. Rio de Janeiro, Nova Aguilar, 1988, p.188.
} 
A primeira entrevistada é Mary Sheila interpretando Jeckie Brown. A pessoa interpretada e a intérprete são oriundas da periferia carioca e participam de um mesmo grupo de teatro. Em seus últimos instantes na tela, Mary Sheila - a atriz - simula ser a outra atriz representando Joana, personagem de Gota D'Água, peça de teatro escrita em 1975, quando Chico Buarque de Holanda e Paulo Pontes renovaram a lembrança de Medeia. No contexto do filme, a menção às figuras de Joana e de Medeia traz à superfície forças arquetípicas, preparando o público para aspectos que irão reverberar ao longo dos diversos depoimentos. Com poder emblemático, essas figuras femininas evocam passionalidade amorosa, capacidade de reação, maternidade em confronto com a vida e com a morte. Mais adiante, a própria Jeckie Brown complementa a sua história.

As demais entrevistadas falam de várias experiências. Duas relatam mortes de filhos. Gisele Alves Moura, cujas aparições na tela alternam com as de Andréa Beltrão, atriz que a interpreta, perdeu o filho Vitor logo após o nascimento; Claudiléia de Lemos teve um filho assassinado. Débora Almeida interpreta Nilza, trabalhadora doméstica cuja filha nasceu de sexo casual. Embora narre em tom confessional um rito de passagem realizado em candomblé, a atriz Fernanda Torres representa principalmente Aleta Gomes Vieira, uma jovem que, atormentada pela doença da mãe, divide-se entre o amor por sua filha e a sensação de que, ocorrida prematuramente, a maternidade mutilara os seus projetos. Maria de Fátima Barbosa fala de sua depressão motivada pela descoberta de que o marido tivera relacionamento homossexual. Marina D’Elia, atriz, apresenta a sua própria experiência envolvendo sentimento de culpa pela morte do pai. A entrevista de Sarita Houle Brumer será comentada mais adiante.

Os depoimentos conferem destaque aos vínculos familiares. Conforme observa Coutinho, em comentário feito no DVD, acontecimentos públicos não são mencionados. As falas concentram-se na vida privada, nos vínculos partidos e nas consequências criadas por essas rupturas. Como as entrevistadas são mulheres, é justo qualificar o imaginário que se depreende do conjunto como feminino. O discurso pluripessoal que veicula esse imaginário gira em torno de estruturas que, como ervas rasteiras e pouco visíveis, germinaram sobre os escombros da sociedade patriarcal quase completamente arruinada no Brasil do século XXI. Nesses grupos familiares, o pai é pouco presente, é aquele que se afastou ou jamais existiu, de modo que o núcleo fica constituído pela mãe e pelos filhos. Ecoa, nas diversas falas, uma sombra ameaçadora. Trata-se da dissolução desse vínculo entre mãe e filhos. Sustentando-se em si mesmo, mas também ostentado como um desafio, esse núcleo parece representar um último reduto para a noção de família. Assim, a ideia da 
sua extinção não apenas abala a identidade, mas talvez também faça estremecer o conceito de humanidade.

As falas são todas movimentadas pela confissão da dor e pela tentativa de superá-la, não pela ocultação do trauma, mas antes por sua franca exposição. Há, portanto, na composição familiar feita de mãe e filhos, um sentido de resistência, ainda que essa resistência não seja feita sem esforço e sem sofrimento. Uma capacidade regenerativa é exibida, por todas as mulheres, com insistência. Peças de teatro, canções e filmes são convocados, a fim de auxiliar a simbolização da dor e, em decorrência, o trabalho do luto. As lembranças de outros contextos familiares persistem. Em relação a eles, há ambivalência e melancolia. Esse é o caso da depoente destacada a seguir.

As cenas de Sarita Houli Brumer mantêm alternância com as da conhecidíssima atriz Marília Pêra, que a interpreta de modo contido e distante do gestual afetado da depoente. Tenso entre a lembrança do pai e a problemática relação com a filha, o depoimento de Sarita ajuda a enxergar, em quase todos os outros, substratos rebeldes ao trabalho do luto. Da mesma forma, a sua fala lança luz sobre dois aspectos marcantes no discurso pluripessoal que Coutinho leva às telas: a descontinuidade da tradição patriarcal e a sombra da esterilidade evocada no fantasma de rompimento com os filhos. Juntos, esses traços também rondam a literatura brasileira, desde o século XIX, onde, provavelmente, funcionam como respostas dialéticas às promessas de futuro inerentes a projetos modernizadores de variada natureza: "Não tive filhos", exclama Brás Cubas, ao encerrar as suas Memórias Póstumas. "Doeu-me que Ezequiel não fosse realmente meu filho, que me não completasse e continuasse", 4 confessa Bento, aos leitores de Dom Casmurro.

Reumatologista obrigada a diminuir seu ritmo de trabalho por conta de uma hepatite autoimune, Sarita Houli Brumer é filha de mãe católica convertida ao judaísmo para se casar com um médico judeu. Quanto ao pai, ela o apresenta como bumanista genial, Senhor na própria Casa, sempre à espera da esposa, para serví-lo. Sarita não hesita em identificar a lembrança da passionalidade paterna como um bálsamo usado contra todas as suas dores: 0 que me salvou na vida foi a paixão de meu pai. Ao destacar o papel submisso e servil reservado à mulher no contexto da sua família de origem, ela não deixa de emitir nota crítica em relação a esse sistema tradicional. No entanto, a sua consciência dos limites que envolvem o grupo familiar guardado na lembrança não impede que o evoque com orgulhosa identificação e pungente saudade.

${ }^{4}$ MACHADO DE ASSIS. Obra Completa, v I. Rio de Janeiro: Nova Aguilar, 1992. p. 639 e p.942. 
Em seu compósito de ironia e afeto, o depoimento de Sarita evidencia com nitidez que, embora o contexto focalizado por Coutinho seja escassamente representado na literatura brasileira, o imaginário que nele circula mantém, com essa literatura, zonas de atrito e de contato. Lembro que, embora seja crítica em relação ao contexto repressor da sua infância, a voz que fala ao longo de todo o percurso poético realizado por Carlos Drummond de Andrade jamais conseguiu obter, por ato de transferência, um modo de pertença que compensasse o esgarçamento dos laços familiares tradicionais. Ao extrair quadros poéticos da própria biografia, Drummond ilustrou um mundo patriarcal que, tendo invadido o século XX brasileiro, tem raízes fincadas na colônia. Nesse sentido, elementos contidos em suas cenas podem ser postos em diálogo com o paradigma de Gilberto Freyre, ${ }^{5}$ cuja forma terminou por se inscrever no imaginário de todo o país. ${ }^{6}$

Pertencendo a contextos históricos bastante diferentes, os quadros inscritos nas memórias do poeta mineiro e da médica paulista convergem para a primeira das três composições familiares ocidentais descritas por Elizabeth Roudinesco, em seu estudo $A$ Família em Desordem. ${ }^{7}$ Ambos se reportam à irrestrita autoridade do pai, visto como um ser que dava segurança à família, assim como um Deus devia garantir a estabilidade do Cosmo.

Mas o depoimento de Sarita não se restringe à casa da infância. Ela casou com um americano, divorciou-se e entrou em conflito com a filha única. Como a mãe de Luisa Porto, aquela persona lírica criada por Drummond, em 1948, Sarita busca desesperadamente a filha que se afastou. Em suas próprias palavras, seu objetivo na vida é recompor o elo partido com a única descendente. Marília Pêra representa o trecho que informa o seguinte: agredida fisicamente pela mãe, a moça chamara a polícia. Desde então, o laço entre mãe e filha sofrera ruptura. Espantada com a atitude da filha, Sarita enfatiza o choque entre as diretrizes que norteavam o seu grupo de origem e os vetores que orientam a sua descendente: Meu pai batia. Eu apanhava e achava que o amor persistiria como um anel incapaz. de romper-se.

Nesse caso específico, o transplante cultural e os diversos casamentos interculturais o do pai com uma brasileira e o seu próprio com um americano - possivelmente facilitaram

\footnotetext{
5. In: FREYRE, Gilberto. Casa Grande e Senzala; formação da família brasileira sob o regime da economia patriarcal. In: SANTIAGO, S. (coord.) Intérpretes do Brasil, v. II. Rio de Janeiro, N. Aguilar, 2000-2002.p.121-645. Conferir principalmente o capítulo I: Características Gerais da Colonização Portuguesa do Brasil: formação de uma sociedade agrária, escravocrata e híbrida

${ }^{6}$ Mesmo contestando o vasto alcance que Freyre atribui à forma descrita em Casa Grande e Senzala, Florestan Fernandes considera que algumas diretrizes do mundo senhorial tiveram, de fato, ampla assimilação, no que tange às relações pessoais entre pai e filhos, marido e mulher.. Cf: “...afora as relações pessoais entre pai e filhos, marido e mulher, senhor e escravos e senhores entre si, tais homens concediam-se extrema liberdade para agir independentemente do código de ética senhorial." FERNANDES, Florestan. A Revolução Burguesa no Brasil. In: SANTIAGO, S. (coord.) Intérpretes do Brasil, v. II. Rio de Janeiro, N. Aguilar, 2000-2002. p.1616.

${ }^{7}$ ROUDINESCO, Elizabeth. A Família em Desordem. Rio de janeiro, Jorge Zahar, 2003.
} 
o desgaste dos valores e acentuaram as diferenças entre as posturas adotadas pela mãe e pela filha, em relação aos vínculos familiares. ${ }^{8}$

Certamente, o choque entre tradição e modernidade também perpassa o conflito existente entre Sarita e a sua filha radicada na América. A visão tradicional da médica confronta-se com a noção moderna da filha, que evoca, contra a falta de limites da mãe, a interferência do Estado. Afirmando que o patriarca moderno passou a ser constantemente ameaçado pela emersão do feminino e questionado pelas teorias psicanalíticas, Elizabeth Roudinesco também lembra que os princípios laicos da Modernidade enfraqueceram os laços de sangue e acrescenta que, na família moderna, a autoridade familiar passou a ser limitada pelo Estado, instituição co-responsável pela condução dos filhos. Dessa forma, ao aderir afetivamente ao sistema tradicional preconizado pelo pai, que por sua vez continuava a visão do avô, Sarita dificilmente aceitaria que a filha atribuísse à polícia o poder de interferir em desavenças familiares.

Ao refletir sobre a família atual, Roudinesco considera que o fenômeno de sucessivos divórcios e as uniões entre pessoas do mesmo sexo determinam a formação de tribos insólitas, redes assexuadas, fraternas, sem hierarquia nem autoridade. ${ }^{9}$ Essa nova ordem familiar é, em sua perspectiva, um valioso refúgio contra as angústias, fonte de um equilibrio que não pode ser proporcionado pela vida social. ${ }^{10}$ Evidentemente, tradição, modernidade e contemporaneidade convivem na vida social brasileira e, portanto, as três composições familiares descritas por Elizabeth Roudinesco também aparecem, na literatura nacional, com zonas de intersecção. No entanto, no que tange à expectativa traçada pela ensaísta em relação à família atual, cabe observar que, embora com desvio diverso daquele que se estabelece na literatura brasileira, ela também não contempla o quadro descrito pelas mulheres entrevistadas em Jogo de Cena, menos ainda a dor contida no discurso pluripessoal que ali se configura.

Verdade que, com certa frequência, os escritores modernistas tentaram inserir, dentre as marcas que particularizariam a vida social do país, a específica importância que supostamente teria a mulher na sua organização familiar. Nesse percurso, usaram moldura utópica, herdada de um Romantismo que depois se manteve com distorções, em narrativas

\footnotetext{
8 Tal problemática concernente aos transplantes culturais e aos conflitos familiares por eles gerados foi matéria tratada por Raduan Nassar, em Lavoura Arcaica, (1975), e, mais recentemente, por Milton Hatoum, em quase todos os seus romances. No entanto, esses escritores focalizam prioritariamente a agonia do patriarcado.

${ }^{9}$ Ibid.,p 155.

10 Ibid., p.153.
} 
destinadas a um grande público. ${ }^{11}$ Em contrapartida, a despeito de toda resistência que demonstram e que, de certa forma, ostentam, as mulheres entrevistadas por Coutinho não usam tintas idealistas, menos ainda as usa Sarita Houli Brumer.

Única entrevistada a pedir para retornar à tela, Sarita alegou anseio de diminuir a nota melancólica marcante em seu depoimento. Todavia, o seu retorno termina por potencializar a melancolia. A despeito da sua capacidade de rir da própria dor, a entrevistada apontou apenas o filme de Eduardo Coutinho como esperança tênue de que a sua insatisfatória situação se alterasse. Cantando uma cantiga de roda montada sobre a bela alegoria de um bosque chamado solidão, Sarita Houli Brumer encerra Jogo de Cena, enquanto a voz de Marília Pêra ecoa, juntando-se à sua como um duplo solidário. Esse desfecho marca com nitidez o compromisso do cineasta. Ele parece afirmar, nesses momentos finais, o fato de que o seu filme estrutura-se com compassiva cumplicidade, constituindo gesto de solidariedade cultural pouco frequente, em relação a esse quadro permeado por sofrimento. E esse sofrimento agrava-se, à medida que se ampliam as lacunas deixadas pelo Estado brasileiro, no que tange à proteção da mulher, da sua saúde, da sua integridade física e emocional.

Gostaria de finalizar observando que, tal como acontece em outros filmes do mesmo diretor, Jogo de Cena reedita, em nova versão, o anseio de conhecimento e representação da realidade social do país, proposto na década de $1930{ }^{12}$. No entanto, o filme de 2007 agrega, a esse anseio, uma consciência posterior, que pôs em xeque a representação de alteridades. Em Vidas Secas, Graciliano Ramos, ao atribuir pensamentos à cachorra Baleia, levou o seu projeto ao absurdo e, assim, ironizou a literatura que praticava. Assumindo a máscara de Rodrigo, angustiado entre o falseamento e a revelação da alma de Macabéa, migrante nordestina, Clarice Lispector radicalizou a questão. Querendo dar vOz a esse imaginário feminino que está no centro do seu filme, Coutinho pôs em cena os recursos do cinema, questionando-os. Exposta na tela, cada pessoa é evocação e simultaneamente ilusão de uma presença física. Conforme atesta Frédéric Subouraud, há, no cinema, uma zona turva, onde o corpo do ator e a ideia da personagem se combinam e se confundem ${ }^{13}$. Todavia, em seus momentos finais, quando, à imagem e ao canto de Sarita, soma-se o canto da atriz famosa, os recursos do cinema parecem concentrados nesse autoquestionamento, mas igualmente concentrados

\footnotetext{
${ }^{11}$ Sem considerar camadas espessas de idealismo, não se podem entender as heroínas propostas nas novelas de televisão escritas por Aguinaldo Silva. Abandonadas, deixadas com o encargo das famílias, elas ultrapassam todos os obstáculos sociais, enriquecem e conseguem realização afetiva na maturidade.

12 Ao introduzir o livro de Sérgio Buarque de Holanda, Raízes do Brasil, Antonio Cândido refere-se a um "sopro de radicalismo intelectual e análise social." Cf: SANTIAGO, S. (coord.) Intérpretes do Brasil, v. II. Rio de Janeiro, N. Aguilar, 2000-2002.p.931.

13 SUBOURAUD, Frédéric. La adaptación: El cine necesita historias. Madrid, Espasa Libros, 2010.p.52.
} 
no esforço de transcender toda psicologia individual, a fim de que os sentidos universais, aqueles que emanavam das antigas personas teatrais, finalmente se imponham. Há uma verdade que se revela a partir das entrevistadas, ainda que todas elas, em alguma medida, executem solidários exercícios de interpretação.

\section{REFERÊNCIAS}

DRUMMOND DE ANDRADE, Carlos. Poesia e Prosa. Rio de Janeiro: Nova Aguilar, 1988. COUTINHO, Eduardo. Jogo de Cena. DVD contendo Filme, Extras, Faixa Comentada por Eduardo Coutinho, João Moreira Salles e Carlos Alberto Mattos. Rio de Janeiro: Videofilmes, 2008.

Site do Instituto Brasileiro de Geografia e Estatística. www.ibege.gov.br

MACHADO DE ASSIS. Obra Completa, v I. Rio de Janeiro: Nova Aguilar, 1992.

RISÉRIO, Antonio. Caymmi: uma utopia de lugar. São Paulo: Perspectiva/Salvador, Copene,1993.

ROUDINESCO, Elizabeth. A Família em Desordem. Rio de janeiro: J. Zahar, 2003.

SANTIAGO, S. (coord.) Intérpretes do Brasil, 3 v. Rio de Janeiro: Nova Aguilar, 2000-2002.

SUBOURAUD, Frédéric. La Adaptación: El cine necesita historias. Tradução para o espanhol de Alica Capel Tatjer. Madri: Espasa libros, 2010.

TELES, Gilberto Mendonça. Vanguardas Européias e Modernismo Brasileiro: apresentação e crítica dos principais manifestos vanguardistas. Petrópolis: Vozes, 1977 